\title{
A derrotabilidade na teoria dos princípios
}

\author{
Defeasibility in theory of principles
}

\section{Anizio Pires Gavião Filho* Alexandre Prevedello**}

\section{Resumo}

\begin{abstract}
A adequação das normas jurídicas a casos particulares é um dos aspectos mais relevantes do Direito, sendo que a noção de derrotabilidade (defeasibility), introduzida no âmbito jurídico por Herbert L. A. Hart, é um dos seus temas mais polêmicos, pois versa sobre a capacidade daquelas acomodarem exceções implícitas sem perderem sua força normativa. O ensaio investiga como tal fenômeno jurídico repercute na teoria dos princípios, utilizando-se a obra de Robert Alexy como parâmetro. Inicia-se diferenciando regras de princípios, enfatizando que as regras possuem caráter prima facie diante da possibilidade de se sujeitarem a uma cláusula de exceção. Defende-se que a derrotabilidade é uma característica exclusiva das regras jurídicas, tanto legislativas como jurisprudenciais; princípios, por sua vez, não são derrotáveis. E as regras possuem primazia sobre os princípios no sentido de que representam o produto da ponderação por quem detém autoridade normativa. Afirma-se, ainda, que a força irradiante dos princípios sobre o sistema jurídico é a responsável por atribuir juridicidade a uma decisão contra legem. Por fim, esclarece-se que a derrotabilidade pressupõe uma colisão entre regra e princípio, cujos métodos principais para resolução são o exame de proporcionalidade ou a ponderação envolvendo princípios formais e materiais. Conclui-se que a derrotabilidade é uma característica do Direito que atribui relevante função aos tribunais para a manutenção de um sistema jurídico equilibrado.
\end{abstract}

Palavras-chave: Derrotabilidade. Regras. Princípios. Exceções.

\section{Abstract}

The adequacy of general legal standarts to particular cases is one of the most relevant aspects of Law, being the notion of defeasibility, introduced to the legal area by Herbert L. A. Hart, one of its most polemic themes as it is about the capacity of legal standarts to accommodate implicit exceptions without losing its normative power. This essay investigates the way this legal phenomenon repercussions in the Theory of Principles, using the work of Robert Alexy as a parameter. It starts differentiating rules to principles and emphasizing that rules have a prima facie character due to the possibility of being submitted to an exception clause. It defends that defeasibility is an exclusive characteristic of rules, as legislatives and as judicial precedent; principles, on the other hand, are not defeasible. It also states that the rules have primacy over the principles in the sense of representing the product of weighting of those who hold the regulatory authority. It is further stated that the irradiance power of the principles over the legal system is responsible for attributing legality to a contra legem decision. Lastly, it clarifies the idea that defeasibility presupposes a collision between rule and principle, whose main methods to resolution are the proportionality examination or the weighting involving formal and material principles. This essay concludes that defeasibility is an inherent characteristic to the Law that attributes a significant function to courts in the maintenance of a balanced legal system.

Keywords: Defeasibility. Rules. Principles. Exceptions.

Doutor em Direito pela Universidade Federal do Rio Grande do Sul. Professor do curso de graduação em Direito da Fundação Escola Superior do Ministério Público. Procurador de Justiça do Ministério Público do Estado (MP-RS). Porto Alegre - RS - Brasil. E-mail: piresgaviao@hotmail. com.

Mestre em Direito na Fundação Escola Superior do Ministério Público. Assessor de Desembargador - Tribunal de Justiça do Estado do Rio Grande do Sul. Especialização em Processo Civil pela Universidade Federal do Rio Grande do Sul. Especialização em Direito Constitucional pela Universidade do Sul de Santa Catarina. Porto Alegre - RS - Brasil. E-mail: aleprevedello@hotmail.com. 


\section{Introdução}

Um dos aspectos relevantes da teoria do Direito diz com a formulação de padrões gerais de conduta que têm como objetivo regular a convivência em sociedade. A compreensão exata da importância e das diferentes funções das normas jurídicas, sua forma de aplicação a casos particulares e, principalmente, o reconhecimento de seus limites para a resolução satisfatória de todos os casos concretos, é essencial para o desenvolvimento contínuo do Direito.

A positivação por si só não garante certeza e segurança jurídica, visto que as normas jurídicas e também os precedentes judiciais sofrem limitações que decorrem da indeterminação da linguagem e da impossibilidade de previsão antecipada de todas as particularidades que podem se apresentar quando da resolução de um caso particular.

Nesse sentido, Herbert L. A. Hart (2001), ao reconhecer, primeiramente, o caráter derrotável dos conceitos jurídicos e, em um segundo momento, o caráter derrotável das normas jurídicas, isto é, sua capacidade de acomodar exceções implícitas sem perder sua força normativa, introduziu no âmbito do Direito a noção de defeasibility - o termo em inglês tem sido traduzido para o português ora como derrotabilidade, ora como superabilidade.

Um caso relevante ilustra perfeitamente uma hipótese de tal fenômeno jurídico: na ADPF 54, o Supremo Tribunal Federal reconheceu ser "inconstitucional interpretação de a interrupção da gravidez de feto anencéfalo ser conduta tipificada nos artigos 124, 126 e 128, incisos I e II, do Código Penal". ${ }^{1}$

Sob o enfoque da defeasibility, houve o reconhecimento pelo judiciário de uma exceção implícita à regra jurídica geral de ser proibido o aborto ao não aplicar a consequência jurídica disposta na lei, ainda que presentes as condições abstratas formuladas pelo legislador. Essa exceção implícita se vincula às outras duas exceções expressas constantes da lei penal de se autorizar o aborto quando não há outro meio de salvar a vida da gestante e em caso de gravidez resultante de estupro. Em uma formulação simplificada, no sistema jurídico brasileiro, hoje, é vedada a interrupção da gravidez, a menos que (a) para salvar a vida da gestante, (b) em caso de estupro e (c) na hipótese de o feto ser anencefálico.

A derrotabilidade, portanto, remete à ideia de exceções no Direito, as quais devem ser deixadas para reconhecimento por parte dos tribunais. Não é difícil perceber que isso representa um significativo risco à segurança jurídica, assim como pode gerar um protagonismo excessivo do judiciário, sobretudo no atual cenário jurídico nacional, porque, ao mesmo tempo em que se consolida a teoria dos princípios como uma teoria das normas (modelo de sistema jurídico composto por regras e princípios), valorizam-se excessivamente os princípios constitucionais em detrimento das regras jurídicas infraconstitucionais.

O objeto central do presente estudo, portanto, é investigar como o fenômeno da derrotabilidade relaciona-se com a teoria dos princípios, adotando-se como parâmetro a obra de Robert Alexy. Examinase como ela interage com as diferentes espécies normativas (princípios e regras) para fins de garantir racionalidade e juridicidade às decisões judiciais que reconheçam uma exceção implícita a uma regra infraconstitucional (decisões contra legem).

O desenvolvimento do trabalho ocorrerá em cinco etapas. Primeiro, faz-se uma breve distinção entre as normas que compõem a teoria dos princípios, enfatizando o caráter prima facie das regras. Segundo, trata-se da noção de defeasibility para Hart, com a adoção de um conceito que será pressuposto do ensaio. A partir disso, será investigado se a derrotabilidade é uma característica comum aos princípios ou exclusiva das regras. Em seguida, as diferentes funções das normas jurídicas são referidas, assim como o papel dos princípios jurídicos na derrotabilidade de uma regra. Por fim, apresentam-se as metodologias que estruturam a argumentação jurídica no caso de colisão entre regra e princípio.

BRASIL. Supremo Tribunal Federal. ADPF 54. Relator: Min. Marco Aurélio, Tribunal Pleno, julgado em 12/04/2012, Acórdão Eletrônico DJe-080, divulgado em 29/04/2013, publicado em 30/04/2013, RTJ vol-00226-01, p. 00011. 


\section{Teoria dos princípios como uma teoria normativa: a distinção entre regras e princípios}

Atualmente, é consenso no sistema jurídico nacional, em especial a partir da configuração da Constituição Federal de 1988 e da atuação cada vez mais relevante do Supremo Tribunal Federal, inclusive na definição (ou formulação) de padrões gerais de conduta, que "o modelo de sistema jurídico do Estado de Direito constitucional democrático não pode ser outro senão um modelo de regras e princípios" (GAVIÃO FILHO, 2011, p. 29).

Um sistema jurídico equilibrado - no sentido de ser previsível, estável, coerente e, ao mesmo tempo, com abertura suficiente para se adequar às particularidades excepcionais que podem surgir - não depende apenas da atuação do legislador ao utilizar adequadamente princípios e regras para fins de orientação da vida em sociedade; é preciso também que eles "funcionem e sejam manipulados pelos operadores jurídicos dentro de suas características próprias" (BARCELLOS, 2005, p. 187).

No entanto, verifica-se - em grande parte também a partir da atuação do Supremo Tribunal Federal - a falta de critérios no enquadramento das referidas espécies normativas, circunstância que prejudica a coerência e a racionalidade das decisões, sobretudo porque a distinção entre regras e princípios é "uma das colunas-mestras do edifício da teoria dos direitos fundamentais" (ALEXY, 2014, p. 85) ou, em outra formulação, o teorema da identificação exclusiva (toda norma é ou regra, ou princípio) é o "axioma central da teoria dos princípios" (BACKER, 2011, p. 57).

Como critérios clássicos, normalmente são referidas as distinções qualitativas e fortes, formuladas inicialmente por Ronald Dworkin e aprofundadas por Robert Alexy.

Para Dworkin, a diferença básica decorre da natureza da orientação que oferecem na regulação de padrões de conduta: as regras válidas determinam, obrigatoriamente, a decisão a ser tomada e, portanto, são aplicadas na forma "tudo ou nada", enquanto os princípios não possuem tal pretensão de definitividade, pois apenas enunciam fundamentos para direcionamento dos argumentos jurídicos em determinado sentido. Os princípios possuem como atributo exclusivo uma dimensão de peso ou de importância, quer dizer, em caso de colisão com outro princípio, o de maior densidade prevalecerá, e será utilizado como fundamento da decisão, enquanto as colisões entre regras são definidas necessariamente pela invalidade de uma (DWORKIN, 2002, p. 39-42).

O conceito de norma para Alexy (2014, p. 87-91) também abarca princípios e regras, porque ambos dizem o que deve ser, isto é, enquadram-se como expressões deônticas do dever, da permissão e da proibição. A diferença é qualitativa e o "ponto decisivo" é: princípios são mandamentos de otimização satisfeitos em graus variados, a depender das possibilidades fáticas e jurídicas, enquanto regras possuem determinações - ou mandamentos definitivos - que são sempre satisfeitas ou não satisfeitas.

Essa diferença fica perceptível na forma da solução dos casos de colisão (entre princípios) e de conflitos (entre regras): quando duas regras conflitam, ou se introduz uma exceção a uma delas - se isso for possível - ou se declara inválida uma delas, pois o conceito de validade jurídica não possui graduação. Quando dois princípios colidem em um caso concreto, um deles cede, sem que se declare a invalidade do outro ou se opere uma exceção, até porque, em condições diversas envolvendo os mesmos princípios, pode ocorrer a inversão da solução. Então, os conflitos/colisões ocorrem em diferentes dimensões: de validade, em caso de regras, e de peso, no caso dos princípios (ALEXY, 2014, p. 92-94).

Ao contrário de Dworkin - para quem apenas os princípios possuem um caráter prima facie -, Alexy (2014, p. 104) afirma que as regras também são dotadas de tal atributo exatamente pela capacidade de acomodar exceções introduzidas pelo judiciário, que acabam por fulminar sua pretensão de definitividade absoluta.

Esse caráter prima facie das regras decorrente da possibilidade de se realizar uma redução teleológica no seu âmbito de incidência é distinto daquele que se atribui aos princípios.

Aos princípios reconhece-se o seu caráter prima facie porque a extensão de seus conteúdos não é plenamente definida e definitiva, visto que dependem do exame das possibilidades fáticas e jurídicas 
(princípios contrários e regras limitadoras). Por outro lado, o caráter prima facie das regras decorre tão somente da possibilidade de elas virem a falhar, no sentido de ser necessário reconhecer uma exceção.

É possivel sintetizar o raciocínio na seguinte formulação: os princípios possuem um caráter inerentemente prima facie, enquanto as regras possuem um caráter excepcionalmente prima facie. Ainda que se objetive o fortalecimento do caráter prima facie dos princípios, de modo algum é possível igualá-lo àquele atribuído às regras, pois o caráter prima facie destas se baseia em decisões tomadas por autoridades legitimadas pelo sistema jurídico, ou seja, "continua a ser algo fundamentalmente diferente e muito mais forte" (ALEXY, 2014, p. 106).

Pode-se dizer, assim, que há uma distinção que decorre da estrutura dos direitos garantidos. As regras garantem direitos ou impõem deveres definitivos, enquanto os princípios garantem direitos ou impõem deveres prima facie. O direito definitivo de uma regra significa que deverá ser realizado totalmente, ainda que as regras suportem exceções (momento em que se revela o seu caráter prima facie). $O$ direito prima facie de um princípio significa que a realização é apenas parcial, no sentido de que há um caminho a ser percorrido entre o direito ou dever prima facie e aquilo que é garantido ou imposto de modo definitivo (SILVA, 2010, p. 44-45).

O objetivo aqui não foi o de descrever todas as discussões teóricas e práticas que o tema envolve, ${ }^{2}$ mas reproduzir alguns dos critérios mais relevantes para fins de facilitar a compreensão da formulação proposta nos próximos capítulos: o termo derrotabilidade, no sentido mais consentâneo com a sua origem - o da capacidade jurídica de acomodar exceções -, pressupõe uma norma do tipo regra.

\section{0 surgimento e o significado de defeasibility das normas jurídicas}

A palavra inglesa defeasibility é utilizada por diferentes áreas do conhecimento que se dedicam ao estudo da relação regra/exceção, como a Lógica, a Epistemologia e a Filosofia (BELTRÁN; RATTI, 2012a, p. 01).

No âmbito do Direito o tema versa sobre a adequação das normas gerais aos casos particulares e é empregado para designar fenômenos jurídicos com significados e objetos distintos, sendo comum o emprego de expressões como derrotabilidade ou superabilidade (a) normativa, (b) das regras jurídicas, (c) dos princípios jurídicos, (d) do raciocínio jurídico e (e) dos conceitos jurídicos. ${ }^{3}$

Embora não seja possível assegurar com absoluta certeza que foi Hart quem primeiro apresentou a noção de defeasibility no âmbito da Filosofia do Direito, ${ }^{4}$ não há equívoco em afirmar que o termo foi cunhado por ele ao qualificar ou simbolizar o caráter derrotável dos conceitos jurídicos no ensaio The Ascription of Responsibility and Rights (1949, p. 171-194).

Hart (1949) tinha como objetivo principal demonstrar que a principal função dos conceitos na linguagem ordinária e na jurídica não é descritiva de coisas, eventos ou pessoas, mas sim atributiva (ascriptive) de responsabilidade e de direitos (reivindicar, reconhecer, atribuir e transferir direitos, e admitir ou atribuir acusações de responsabilidade). Assim, a função dos juízes não é responder, positiva ou negativamente, ao questionamento acerca da inserção dos fatos do caso dentro do escopo da fórmula que define as condições necessárias e suficientes dos conceitos jurídicos (HART, 1949, p. 171).

Por isso não foram citadas as críticas que Humberto Ávila (2015) faz sobre a distinção elaborada por Alexy. Um exame mais aprofundado das sistematizações de Dworkin, Alexy e Ávila encontram-se na obra "Argumentação contra legem: a teoria do discurso e a justificação jurídica nos casos mais difíceis", de Thomas da Rosa Bustamante (2005, p. 183-231).

3 Jorge Luis Rodríguez e Germán Sucar (2003, p. 103-155) catalogaram onze circunstâncias ou sentidos ordinariamente referidos como causadores de la derrotabilidad no Direito.

4 A doutrina praticamente converge no sentido de que o conceito de defeasibility foi originalmente formulado por Hart no ensaio acima referido. Fernando Andreoni Vasconcellos (2010, p. 53-54) relaciona vários doutrinadores que o citam como o criador do conceito, como, por exemplo, Henry Prakken, Giovanni Sartor, Juan Carlos Bayón, Neil MacCmormick, Jaap Hage e Rounald P. Loui. Por sua vez, Giorgio Pino (2010, p. 09) prefere afirmar que uma das primeiras introduções da derrotabilidade no discurso jurídico foi realizada por Hart neste ensaio de 1949, enquanto Carsten Bäcker (2011, p. 61) acredita que tal noção foi introduzida por Hart. 
Ao explicar que uma característica distinta - e talvez a principal - dos conceitos jurídicos decorre do uso da palavra unless (a menos que), o que significa que, em várias situações, eles só se explicam com uma lista de exceções ou de exemplos contrários, Hart (1949, p. 174-175) introduz pela primeira vez a palavra defeasible no campo da Filosofia do Direito.

Como exemplo ele apresenta uma lista de circunstâncias capazes de derrotar o conceito de contrato, ainda que todas as condições necessárias e suficientes tenham sido satisfeitas, como a coação e a falsidade, e algumas que não afetam sua existência e validade, como a prescrição (HART, 1949, p. 176).

Isto significa a impossibilidade de se falar em condições sempre suficientes e necessárias, pois, quando se está atribuindo responsabilidade a alguém, circunstâncias novas - impossíveis de serem previstas antecipadamente - podem surgir e tornam necessário refazer o julgamento. Isto corresponde a uma responsabilidade prima facie $^{5}$ à medida que pode ser derrotada por exceções.

Como Hart recebeu críticas à tese do atributivismo (ascriptive) e não mais a mencionou em suas obras posteriores, os termos defeasibible ou defeasibility, parte da doutrina afirma que houve o abandono da doutrina acerca do caráter derrotável dos conceitos jurídicos. ${ }^{6}$

Entretanto, no capítulo VII - Formalismo e ceticismo sobre as regras - do livro O conceito de Direito, o tema é retomado com enfoque na imprecisão e na textura aberta do Direito quando da acomodação das hipóteses gerais aos casos concretos, que não se limita a problemas de linguagem e de interpretação, pois há inúmeras referências a casos em que tais dificuldades não ocorrem, mas, mesmo assim, não se deve aplicar a regra jurídica (HART, 2001, p. 139-168).

Nesse sentido, Hart (2001, p. 152) afirma que é impossível antever todas as possíveis combinações de fatos que podem surgir a partir das regras, o que implica aceitar a "existência de excepções que não são desde logo exaustivamente especificáveis".

Ao exemplificar com um fato cotidiano o fenômeno que está descrevendo, o jurista inglês menciona novamente a expressão unless (a menos que) e acrescenta uma característica fundamental que distingue a defeasibility de outros institutos jurídicos: a capacidade de as regras jurídicas suportarem exceções sem perder sua força normativa (HART, 2001, p. 152-153).

Ante as implicações que o reconhecimento dessa textura aberta do Direito significa para fins de estabilidade e previsibilidade do ordenamento jurídico, Hart (2001, p. 159) conclui, após examinar o papel do judiciário e dos tribunais supremos, que estes somente definem algumas questões particulares sobre as regras, pois, em geral, não geram controvérsias quando de sua acomodação aos casos concretos.

As regras limitam - ao definir padrões de julgamento para uma decisão correta - e, ao mesmo tempo, permitem a atividade criadora dos juízes, sendo que tais padrões nunca são criados pelo judiciário, que apenas se manifesta para mantê-los e delimitá-los cada vez mais.

Assim, o atributo da derrotabilidade é mantido no seu caráter principal, inclusive com o emprego novamente da expressão unless, na acepção de que a adaptação de normas gerais para casos particulares não pode ser realizada sem se considerar a possibilidade de exceções implícitas que implicam no seu reexame, razão pela qual não há falar em condições absolutamente necessárias e suficientes da aplicação de uma regra (tal como de um conceito jurídico); e a regra jurídica excepcionada ainda será uma regra geral válida para outros casos em que for aplicável.

A partir desse breve resumo da obra de Hart, ${ }^{7}$ verifica-se que, desde a sua origem, o conceito de derrotabilidade é relacionado à ideia de exceção, tendo havido uma posterior delimitação do objeto no

Embora o termo - defeasibility - fosse novo, a ideia de representação de deveres e obrigações prima facie já havia sido referida anteriormente por Sir David Ross (na obra The Right and the Good, Oxford: Clarendon Press, de 1930) utilizando a ideia de deveres prima facie em contraponto a Kant e sua concepção de deveres absolutos (BELTRÁN; RATTI, 2012b, p. 22).

6 Neil MacCormick (2010, p. 30) afirma que o ensaio The ascription of Responsability and Rights, que marca o retorno de Hart à filosofia, foi "posteriormente repudiado".

Um excelente estudo acerca da textura aberta do Direito em Herbert Hart e sua relação com a derrotabilidade foi realizado por Patrícia Graeff (2015). 
sentido de que as normas jurídicas possuem como uma de suas características a capacidade de acomodar exceções implícitas, passíveis de reconhecimento pelo judiciário, representando, portanto, uma obrigação prima facie.

Como Hart diferencia as normas jurídicas entre regras primárias e secundárias, ou seja, não as separava entre princípios e regras, é relevante compreender como a derrotabilidade se adapta à teoria dos princípios, sobretudo porque é a concepção atualmente utilizada pelo Supremo Tribunal Federal para fins de resolução dos casos tidos como difíceis.

\section{Derrotabilidade como característica exclusiva das regras jurídicas}

Como já referido, o emprego do termo defeasibility não possui um sentido definitivo na doutrina. Entre os adeptos de um sistema normativo dividido entre regras e princípios, é muito comum a designação derrotabilidade normativa para assinalar uma característica comum às referidas normas ou uma propriedade exclusiva das regras jurídicas.

Nesse sentido, Giorgio Pino (2010, p. 9) afirma que a ideia de derrotabilidade conecta-se com a ideia de exceção no sentido de que uma norma (regra ou princípio) é derrotável se, embora abstratamente aplicável, ela deixe de ser aplicada em razão da presença de alguma condição que a derrote no caso específico.

Do mesmo modo, Fernando Andreoni Vasconcellos (2010, p. 76-77) reconhece a falibilidade de toda norma jurídica, afirmando que, quanto maior o grau de abstração, maior é a chance de isso acontecer, bem como afirma que todo enunciado normativo pode ser reconduzido à formulação hipotético-condicional, ou seja, até um principio pode ser derrotado a partir da lógica clássica.

Em sentido diverso, Anizio Pires Gavião Filho e Rosemeri Munhoz de Andrade (2015, p. 179) sustentam que a superabilidade normativa não inclui princípios, compreendendo apenas as hipóteses "de não aplicação de uma regra jurídica válida quando aplicável", isto é, quando não há dúvida sobre o significado atribuído ao texto normativo, ou, em outros termos, quando se está diante da norma jurídica definitiva, do "enunciado que constitui o produto, o resultado da interpretação" (GUASTINI, 2005, p. 28).

Retornando ao exame da estrutura das regras e dos princípios, é possível asseverar que uma das principais diferenças é a divisão no modo de aplicação: regras aplicam-se por meio de subsunção e princípios, por meio de ponderação.

Não há dúvida, portanto, de que a técnica da subsunção é a que melhor dialoga com a derrotabilidade, pois sua aplicação deve ser de forma estrita, ou seja, determina a consequência jurídica sem possibilidade de graduação. A regra jurídica, portanto, já define, de antemão (passado) e em geral, para todos os casos abstratamente considerados, a conduta que deve ser observada e as eventuais consequências de sua violação no futuro, bastando ao intérprete aplicá-la via subsunção. Logo, a não aplicação de uma regra jurídica válida é um nítido caso em que uma norma é excepcionada.

Por sua vez, a ponderação entre princípios pressupõe um conflito concreto no presente e o exame de todas as particularidades do caso específico para fins de determinação do prevalente, motivo pelo qual Alexy (2014, p. 108) aduz que os princípios considerados em si mesmos (antes da definição de uma relação de preferência a partir das considerações das particularidades apresentadas num caso concreto) nunca laboram como razões definitivas para a criação de normas, mas sim como razões prima facie, do que resulta a impossibilidade de serem sujeitos à exceção, visto que isso pressupõe um dever ou um Direito definitivo.

Note-se que, ao diferenciar regras de princípios a partir do distinto modo de solução para os casos de conflito/colisão, Alexy (2014, p. 93) é claro ao afirmar que o fato de um princípio prevalecer sobre o outro num determinado caso concreto não implica invalidar aquele que cedeu, "nem que nele deverá ser introduzida uma cláusula de exceção", até porque, sob outras particularidades fáticas envolvendo os mesmos princípios, a prevalência pode ser invertida.

Isto significa que a introdução de uma cláusula de exceção não se ajusta à estrutura dos princípios; somente após a ponderação entre princípios - com a elaboração de uma regra jurídica - é que se pode falar em exceção. 
Nesses moldes, Carsten Bäcker (2011, p. 60-61), sustenta, em contraponto às distinções clássicas, que a noção de derrotabilidade é o critério definitivo e que possui o atrativo de uma maior simplicidade para distinguir regras de princípios.

Isto porque as regras jurídicas, entendidas como mandamentos definitivos, geralmente possuem exceções, e nem todas podem ser enumeradas previamente pelo legislador; sendo passíveis, portanto, de ser excepcionadas no futuro a partir das particularidades de um caso concreto. Por sua vez, os princípios jurídicos, definidos como mandamentos de otimização, não têm a capacidade de acomodar exceções, pois o exame de todas as circunstâncias dos casos futuros é inerente ao conceito de otimização e à própria técnica de ponderação.

Então, Bäcker (2011, p. 68) adota uma noção estrita que parte da teoria de Hart: a derrotabilidade é fruto da limitação humana em prever todas as circunstâncias relevantes, o que corresponde a afirmar que há (ante a impossibilidade de se criar uma regra sem exceções) uma deficiência estrutural das regras ("se $a$, então $b$, a menos que $c$ "). Dessa deficiência decorre que a condição em uma regra nunca é completa, pois é utilizado um conjunto de circunstâncias e uma conclusão, sem se considerar outras que podem surgir. Logo, a regra pode ser derrotada, revisada.

Em outras palavras: a definição das regras é sempre prévia e geral, sem considerar todas as particularidades que possam ocorrer. Tem-se a ocorrência do silogismo jurídico: premissa maior é a regra e tem a função de ser universal e hipotética, com um consequente normativo.

Os princípios possuem uma estrutura diferente, porquanto, ao contrário das regras que ordenam a realização de algo sob certas condições, implicam realizar uma finalidade de maneira ótima (otimizar), o que pressupõe considerar todas as circunstâncias relevantes, motivo pelo qual "não pode haver exceções" ou, de outro modo, "não existe 'a menos que' nos princípios" (BÄCKER, 2011, p. 71).

Bustamante (2005, p. 220), que primeiro sustentava que ambas as normas jurídicas eram passíveis de superação, com a diferença de que princípios seriam caracterizados por uma "superabilidade imanente", enquanto as regras teriam uma "superabilidade excepcional", modificou o pensamento para reconhecer o fenômeno como uma característica apenas das regras.

Isto derivou, dentre outros motivos, por também passar a compreender a derrotabilidade na acepção da capacidade de uma norma jurídica admitir exceções. Faz-se pertinente registrar suas próprias palavras:

A principal razão pela qual me afasto deste tipo de explicação do fenômeno da superabilidade é que penso que esta explicação não leva em consideração o fato de os princípios serem normas cuja institucionalização é parcial (já que falta a determinação dos comportamentos concretos que se seguem dessas normas) e, por conseguinte, não poderem ser superadas porque elas não estabelecem nenhuma hipótese de incidência. Os princípios estabelecem apenas uma obrigação de otimizar. Se a superabilidade for definida como a possibilidade de se inserir exceções em uma norma jurídica, então deve-se necessariamente presumir que essa norma tenha a estrutura de uma regra que permita a subsunção de certos fatos ou condutas em sua hipótese de incidência. [...]. (BUSTAMANTE, 2010, p. 153).

Impende ainda um último registro: a defeasibility é uma característica comum às regras legislativas (sistema do civil law) e às regras jurisprudenciais (sistema do common law e sua teoria do precedente judicial), conforme já demonstrava Hart (2011, p. 139), pois ambos os sistemas padecem da mesma dificuldade, ainda que em diferentes níveis de intensidade: revelam-se indeterminados em alguns aspectos e essa textura aberta se revela no momento de sua aplicação.

Nesse momento de aproximação do Direito brasileiro com o common law, especialmente a partir da promulgação do novo CPC (2015), cabe referir que a maioria dos precedentes veicula uma ratio decidendi com estrutura de regra, isto é, com uma estrutura hipotético-condicional que almeja certeza e objetividade para fins de aplicação futura do Direito - através da subsunção dos fatos do caso particular a uma norma universal prévia (BUSTAMANTE, 2012, p. 468). 
Nesse sentido, a não aplicação de uma regra jurisprudencial válida na teoria dos precedentes é conhecida pela técnica da distinção (distinguish), a qual não infirma o teor e o comando de autoridade veiculado pela norma jurídica (hipótese de overruling) ou, consoante Luiz Guilherme Marinoni (2016, p. 231), "não significa que o precedente constitui bad law, mas somente inapplicable law".

O distinguish, então, significa o afastamento da norma apenas em relação ao caso concreto, e se manifesta de duas maneiras: (1) reconhecimento de uma exceção direta (direct exception), que se justifica pelas circunstâncias excepcionais do caso particular - os fatos subsumam-se à hipótese prevista na regra jurisprudencial embora a consequência normativa não seja aplicada, o que acarreta uma redução teleológica no universo dos casos antes compreendidos na norma paradigmática; (2) reconhecimento de uma exceção indireta (indirect exception), isto é, de diferenças fáticas entre o caso particular e aqueles que originaram a regra do precedente; aqui, ao contrário do que ocorre na primeira hipótese, a ratio decidendi mantém-se incólume (BUSTAMANTE, 2012, p. 470-473).

A exceção direta ensejadora da redução teleológica do precedente coincide com a doutrina da derrotabilidade das regras jurídicas no sentido da diminuição do seu âmbito de incidência, que decorre da inserção de uma exceção, significando, nas palavras de Bustamante (2012, p. 474), uma "espécie de retificação do Direito quando este se apresenta injusto por excessivamente geral".

Com a definição de que a derrotabilidade é uma característica exclusiva das regras jurídicas, legislativas ou jurisprudenciais, cabe examinar a função e as formas de interação entre regras e princípios para fins de sua melhor compreensão.

\section{Primazia das regras sobre os princípios e o papel destes na derrotabilidade}

Primeiramente, é necessário retomar a distinção entre regras e princípios, pois a afirmação de que uma regra representa uma obrigação prima facie deve ser bem compreendida, tanto no sentido de que não há incoerência entre admitir a inserção de uma cláusula de exceção a uma regra geral sem invalidar o seu conteúdo normativo ${ }^{8}$ como na acepção de que tal caráter prima facie - por encontrar amparo em uma decisão tomada pela autoridade legitimada ou decorrente de uma prática reiterada - é muito mais forte se confrontado àquele atribuído aos princípios.

Também é imprescindível enfatizar que, ao contrário do que se verifica, especialmente nas decisões do judiciário brasileiro, as regras jurídicas possuem primazia sobre os princípios jurídicos, mas tão somente no sentido que representam - quando se justificam racionalmente - o resultado ou o produto da ponderação entre princípios colidentes realizado por quem detém competência para tanto (em geral, o parlamento) no Estado Democrático de Direito. É apenas uma regra de precedência, na medida em que razões fortes podem afastar inclusive o teor literal de uma regra constitucional (ALEXY, 2014, p. 141).

Até mesmo a alegação ordinária de que os princípios são mais relevantes do que regras por consagrarem valores fundamentais pode ser alvo de objeções, pois (a) princípios jurídicos não se confundem com valor (caráter axiológico ou teleológico) ante seu caráter deontológico, ainda que representem critérios valorativos, características que compartilham com as regras, e (b) a baixa densidade normativa dos princípios (realizar algo na maior medida possível dentro das possibilidades fáticas e jurídicas) não significa proteção superior a determinado bem jurídico do que a realizada por uma regra (HABERMAS, 1997, p. 316-317).

Em realidade, conforme Ávila (2015, p. 148), não é adequado tratar as normas jurídicas que compõem a teoria dos princípios no sentido de indagar qual é a mais importante, e sim compreender que desempenham funções diferentes e complementares.

MacCormick (2008, p. 328), ao final do capítulo 12, intitulado "Argumentação sujeita a exceções (Arguing defeasibly)", conclui que "universais excepcionáveis (defeasible) são, contudo, ainda universais". No mesmo sentido, Bustamante (2012, p. 479) reitera que a superabilidade de uma regra jurídica não implica negação do seu caráter universal. 
A obediência das regras justifica-se não só na ideia de autoridade (devem ser seguidas porque são leis), mas porque pré-determinam escolhas que eliminam controvérsias e incertezas, afastam ou reduzem arbitrariedades passíveis de surgimento na aplicação de valores morais diretamente pelos julgadores, bem como evitam dificuldades de coordenação, deliberação e conhecimento entre as pessoas (ÁVILA, 2015, p. 140-141).

Isto significa que a obediência às regras decorrente de sua força vinculante é um dever imperativo para a coordenação da vida em sociedade; desempenham, portanto, uma função essencial para fins de segurança jurídica, o que não significa dizer que não podem ser excepcionalmente superadas.

Rafael Bellem de Lima (2014, p. 69-90) desenvolve a tese de que a superação de uma regra (no sentido estrito de seu afastamento) é muito mais difícil do que a de um princípio, impondo, portanto, um ônus argumentativo superior, concluindo que as regras devem ter preferência prima facie sobre princípios. Sintetizam-se seus argumentos principais em: (a) a regra é produto da ponderação de princípios realizado por um órgão normativo no exercício de sua competência decisória, o que justifica a sua aplicação de forma estrita (subsunção); (b) as regras asseguram previsibilidade e diminuem o risco de arbitrariedade na aplicação do Direito caso só existissem princípios; (c) a superação de uma regra com base apenas em ponderação de princípios materiais afetaria a alocação do poder decisório previsto na Constituição, que seria transferido ao judiciário, circunstância que tem se tornado frequente no Supremo Tribunal Federal ao realizar a ponderação de princípios desconsiderando a existência de uma regra disciplinando a questão.

Tal formulação coincide com o primeiro parâmetro geral ${ }^{9}$ proposto por Ana Paula de Barcellos (2005, p. 165) para orientar o aplicador do Direito quando da realização de ponderação: "diante de uma situação que exija o emprego da ponderação, as regras (constitucionais e infraconstitucionais) têm preferência sobre os princípios (constitucionais e infraconstitucionais)".

Entre os fundamentos que ensejam a concepção do referido parâmetro ${ }^{10}$ destacam-se as diferentes funções das normas dentro do sistema jurídico para fins de manutenção do equilíbrio. A estrutura das regras, ao impor condutas determinadas, contribui para segurança jurídica (previsibilidade e estabilidade do Direito), enquanto a estrutura dos princípios, mais flexível e aberta, liga-se diretamente à ideia de justiça, no sentido de que são instrumentos que servem para produzir justiça no caso concreto (BARCELLOS, 2005, p. 186-187).

Há, portanto, uma relação de dependência mútua entre as espécies normativas e tal particularidade assume relevância no caso de inserção de exceção a uma regra jurídica válida (decisão contra legem), cuja juridicidade decorre da força normativa dos princípios na argumentação jurídica da decisão. Bustamante ilustra essa situação de maneira precisa:

Em um sistema jurídico de natureza dinâmica, as regras estabelecidas na legislação infraconstitucional não podem ser normas absolutas, ou seja, normas que prevejam uma hipótese de incidência fechada à qual seria impossível admitir exceções. Se a distinção regra/princípio é adotada, então se deve reconhecer que as regras são normas superáveis. Os princípios constituem o material que será empregado na justificação da sua superabilidade. Há duas características dos princípios que são altamente relevantes para a superabilidade. Em primeiro lugar, os princípios, ao contrário das regras, constituem uma institucionalização imperfeita da moral, já que estabelecem apenas um fim ou valor a ser buscado, embora na máxima medida possível. Em segundo lugar, os princípios, tendo em vista o seu caráter axiológico mais acentuado, constituem o fundamento das regras jurídicas (BUSTAMANTE, 2010, p. 163).

Nesse mesmo sentido, MacCormick (2008, p. 311-313) afirma que a defeasibility implícita incide quando, à luz de algum princípio jurídico significativo e de circunstâncias incomuns, o arranjo desenhado

9 O segundo parâmetro geral formulado por Ana Paula de Barcellos (2005, p. 235) considera que as normas que realizam diretamente direitos fundamentais dos indivíduos têm preferência sobre normas relacionadas apenas indiretamente com os direitos fundamentais.

10 Trata-se de uma simplificação dos fundamentos expostos, concluindo a autora que somente quando há colisão de uma regra com o núcleo de um princípio há inconstitucionalidade, ou seja, a regra é preservada se a colisão ocorre com uma área não nuclear do princípio (BARCELLOS, 2005, p. 201). 
pela regra para atingir certos efeitos jurídicos deixa de operar, provocando, portanto, a exceção não prevista em precedente ou na legislação, inclusive quando já há casos de defeasibility expressa, tal como se verifica no caso do aborto do feto anencéfalo julgado pelo Supremo Tribunal Federal. Tal ocorre porque os princípios jurídicos do sistema jurídico interagem com os enunciados legislativos ou com as ratio decidendi dos precedentes vinculantes.

Admite-se, portanto, a formulação de exceções às regras gerais (legislativas e jurisprudenciais), as quais são suficientes para regular a solução dos casos comuns, nas hipóteses em que "eventos particulares põem em operação algum princípio ou valor jurídico de suficiente importância para revogar a suficiência presumível das condições expressamente afirmadas para a atribuição do Direito" (MACCORMICK, 2008, p. 316).

A partir do exposto pode-se afirmar que a derrotabilidade na teoria dos princípios se caracteriza por ser uma colisão entre uma regra e um ou vários princípios, sendo necessário realizar algumas considerações acerca da(s) metodologia(s) empregada(s) para sua resolução satisfatória pelo judiciário.

\section{Colisão entre regra e princípio: métodos que buscam estruturar a argumentação jurídica}

Os princípios aplicam-se por ponderação, enquanto as regras são aplicadas mediante subsunção. A defeasibility das regras pressupõe o conflito entre uma regra e um ou vários princípios; logo, cabe indagar qual método deve ser empregado para a resolução racional da questão pelo julgador.

Conforme Virgílio Afonso da Silva (2010, p. 51), a colisão entre regras e princípios "é talvez o ponto mais complexo e menos explorado da teoria dos princípios", porquanto as três respostas possíveis são problemáticas.

A primeira resposta assevera a realização de uma ponderação entre as normas (princípio e regra) para definir a prevalente, mas afasta o caráter definitivo das regras, além de envolver a dimensão de peso, que não é característica delas. A segunda remete ao plano da validade, pois a norma que ceder terá de ser excluída do ordenamento, inclusive se for um princípio, o que afronta a sua dimensão de peso. A terceira apregoa que se realize uma ponderação entre o princípio conflitante e o que fundamenta, ou justifica, a existência da regra, o que também é insatisfatório, porque possibilita sempre ao Judiciário realizar uma nova ponderação, gerando manifesta insegurança jurídica (SILVA, 2010, p. 51-52).

Lima $^{11}$ (2014, p. 91-159) apresenta e examina criticamente dois métodos que buscam estruturar a argumentação jurídica da decisão judicial no conflito entre um princípio e uma regra, os quais possuem como característica comum conferir às regras uma maior resistência à superação: o exame de proporcionalidade e a ponderação envolvendo princípios formais e princípios materiais.

O exame de proporcionalidade, quando realizado adequadamente (observada fielmente sua estrutura específica e ordenada para fins de exame se a medida adotada é necessária, adequada e proporcional em sentido estrito), evidencia que os órgãos normativos - em especial o legislativo - possuem liberdade para restringir direitos fundamentais, com justificativa na promoção de interesses ou objetivos legítimos, desde que ausentes meios menos gravosos que os promovam com a mesma intensidade, circunstância que mantém o necessário equilíbrio na relação entre os Poderes constituídos, isto é, não gera implicações explosivas (LIMA, 2014, p. 114-115).

Como se orienta pelo grau de promoção e de restrição à realização de direitos, isto é, leva em consideração apenas o conteúdo material das medidas analisadas, o exame de proporcionalidade apresenta uma fragilidade: não é um método que dialoga com o fato de que as regras não apresentam sempre a mesma resistência, ou seja, algumas podem ser revistas com mais facilidades que outras a depender da importância de suas finalidades específicas no ordenamento jurídico (LIMA, 2014, p. 127).

Importante registrar que o estudo de Lima versa sobre a superação no sentido do reconhecimento da invalidade da regra, não havendo, portanto, tratamento específico para o caso de derrotabilidade. 
O outro método - ponderação envolvendo princípios formais e materiais -, além de apresentar três modelos distintos, é utilizado por Bustamante para fins de solução do conflito entre regra e princípio especificamente quando se está diante de um caso de derrotabilidade ou, como prefere, de decisão contra legem.

Para Bustamante (2010, p. 169-173), os conflitos de normas jurídicas ocorrem na dimensão da validade, enquanto as colisões incidem no âmbito da aplicabilidade. A inconstitucionalidade de uma regra, com a sua invalidação e retirada do ordenamento, configura um conflito entre normas; por outro lado, a superabilidade caracteriza uma colisão normativa e assim, a inaplicabilidade da regra somente para aquele caso excepcionado, ou seja, a validade geral da regra permanece intocada.

Nestes casos excepcionalmente difíceis, o princípio constitucional não origina razões suficientes para declaração da invalidade da totalidade da regra infraconstitucional, somente justificando a inserção de uma cláusula de exceção em sua hipótese de incidência. Dito de outro modo: embora a regra não seja inconstitucional por regular adequadamente a grande maioria dos casos previstos pelo legislador, e, desse modo, deva ser mantida no ordenamento, a "sua aplicação no caso concreto leva a uma inconstitucionalidade" (BUSTAMANTE, 2010, p. 174).

A solução dessa colisão normativa entre regra infraconstitucional e princípio constitucional não é encontrada racionalmente com uma nova ponderação entre o(s) princípio(s) materiais conflitante(s) e o(s) subjacente(s) à regra, visto que o legislador, ao realizar antecipadamente a ponderação e formular a regra, atribui consequências relevantes para essa norma, especialmente uma "pretensão de definitividade", que gera previsibilidade e estabilidade ao ordenamento e, assim, uma orientação segura aos cidadãos que não pode ser simplesmente desconsiderada pelo julgador (BUSTAMANTE, 2010, p. 159-160).

Daí por que é necessária uma argumentação especial, que não olvide dos princípios formais, procedimentais ou institucionais que laboram pela manutenção da regra, que são aqueles "que estabelecem que as regras que tenham sido criadas pelas autoridades legitimadas para tanto devem ser seguidas e que não se deve relativizar sem motivos uma prática estabelecida", ou seja, eles não determinam nenhum tipo de conteúdo, mas implicam considerar certo grau de deferência ao legislador legitimado democraticamente (ALEXY, 2014, p. 105).

A inclusão desses princípios formais na ponderação possibilita que as regras possam ser consideradas de modo gradual, isto é, a observância da segurança jurídica e da competência decisória do órgão normativo pode variar de acordo com todas as particularidades da situação em julgamento, o que acarreta um modelo mais transparente e vocacionado ao diálogo institucional (LIMA, 2014, p. 168).

Essa presunção graduada de constitucionalidade dos atos normativos, que decorre da inserção dos princípios formais na ponderação, aproxima o método desenvolvido por Alexy do teste dos três níveis (three tier test) da jurisdição constitucional americana. ${ }^{12}$

Tais testes apregoam a existência de graus variáveis de deferência em relação às normas produzidas pelo legislativo ou pela administração a depender do seu conteúdo e de outras particularidades, como o modo de sua elaboração. Por exemplo: quanto maior for a restrição da norma no tocante a liberdades públicas, como a religiosa, mais rigoroso será o teste; por outro lado, a regulação de atividades econômicas pela administração implica extrema autocontenção judicial na análise da validade da norma.

Então, o efeito irradiante dos princípios sobre todo o sistema normativo fundamenta a derrotabilidade das regras, mas é necessária uma argumentação especial (forte) que conecte os princípios formais ou institucionais (princípios do Estado de Direito e da segurança jurídica) ao princípio material subjacente à regra. O que se quer dizer com isso é que os princípios formais não podem, isoladamente, superar princípios

\footnotetext{
2 O tema é objeto de ensaios de Cleve e Lorenzetto (2015, p. 17-73) e de Sarmento e Souza Neto (2013, p. 119-161), que buscam adaptar às particularidades do sistema jurídico brasileiro tais níveis de intensidade ou de parâmetros diferenciados no exame da constitucionalidade das normas.
} 
materiais de direitos fundamentais, sendo, portanto, necessário que estejam atrelados a princípios materiais (ALEXY, 2014, p. 625).

Por conseguinte, somente em uma hipótese absolutamente excepcional se poderá adicionar uma cláusula de exceção a uma regra, o que significa um aumento do encargo argumentativo do julgador para fins de atribuição de racionalidade e, assim, de juridicidade à decisão. ${ }^{13}$

\section{Considerações finais}

O objetivo principal do artigo consistiu em examinar como a noção de derrotabilidade, caracterizada como a capacidade das normas jurídicas acomodarem exceções implícitas sem perder sua força normativa para regular os demais casos em que são aplicáveis, repercute no âmbito da teoria dos princípios, utilizandose como referencial teórico a obra de Robert Alexy.

Embora a derrotabilidade não pressuponha um sistema jurídico normativo dividido entre princípios e regras, tanto que foi introduzida no âmbito jurídico por Herbert H. L. A Hart, cujo conceito de Direito é embasado fundamentalmente em regras jurídicas, demonstrou-se que tal fenômeno é o responsável por atribuir a estas um caráter prima facie no contexto da teoria dos princípios.

A possibilidade de se introduzir uma cláusula de exceção é uma propriedade exclusiva das regras jurídicas (legislativas e jurisprudenciais), pois somente é possível falar em exceção quando já há direitos e deveres definitivos, fixados previamente e com consequências jurídicas também pré-determinadas. Com efeito, a estrutura dos princípios, em especial o seu caráter prima facie (que significa uma realização apenas parcial e não definitiva antes da ponderação de todas as particularidades do caso concreto, o que ensejará a formulação de uma regra), não se coaduna com a ideia de exceções. Logo, princípios não são derrotáveis.

A característica de derrotabilidade das regras jurídicas, que se justifica pela força irradiante dos princípios sobre todo o sistema jurídico, não significa que sejam normas de menor importância ou facilmente superadas na teoria dos princípios. Ao contrário, elas possuem primazia sobre os princípios, no sentido de que representam o produto da ponderação por quem detém autoridade normativa, quer dizer, por quem possui legitimidade reconhecida pelas constituições do Estado Democrático de Direito.

Por fim, verificou-se que uma das questões problemáticas na teoria dos princípios diz respeito ao método procedimental para justificação racional e, assim, atribuição de juridicidade para a decisão judicial, que insere uma exceção a uma regra jurídica válida, quer dizer, qual o método mais adequado na hipótese de colisão entre uma regra e um ou mais princípios jurídicos.

As metodologias ordinariamente referidas na doutrina - exame de proporcionalidade ou ponderação envolvendo princípios formais e materiais - ainda se encontram em desenvolvimento, entretanto pode-se afirmar que a opção pela ponderação entre princípios formais e materiais aproxima a teoria dos princípios de Alexy à teoria desenvolvida junto à jurisdição constitucional norte-americana na tentativa de equilibrar a relação jurisdição/democracia.

A relevância das questões e das particularidades parciais apontadas acima demonstram a necessidade de um tratamento apurado do fenômeno da derrotabilidade para fins de definir o seu significado e suas implicações na teoria dos princípios, sendo ambos necessariamente ligados a uma teoria da argumentação jurídica, especialmente para fins de impedir a propagação de discursos jurídicos arbitrários e subjetivos, que vão de encontro a um atributo básico e imprescindível de qualquer ordenamento jurídico: a segurança jurídica.

Sobre o problema sempre presente da discricionariedade judicial, destaca-se a ressalva de MacCormick (2008, p. 322): "seja como for, o sopesamento de princípios e valores contra regras expressas, com o objetivo de determinar se eles dão suporte a uma exceção, é, sob qualquer perspectiva, uma questão de julgamento. Algum tipo de discricionariedade está envolvido aqui. Aúnica questão em aberto é saber se isso implica uma escolha judicial puramente subjetiva, ou um julgamento que envolve fatores, em princípio, objetivos. A melhor resposta parece ser a de que há fatores objetivos aqui, mas eles são necessariamente mediados pela subjetividade judicial. O processo é de determinação, não de dedução". 
No entanto, é possível concluir que a aplicação racional da noção de derrotabilidade evidencia que as regras jurídicas preservam sua estabilidade e são, ao mesmo tempo, maleáveis para permitir o desenvolvimento do Direito a partir do reconhecimento de situações não previstas anteriormente, sem acarretar a ruptura completa do sistema - sem a invalidade da regra, que apenas é excepcionada no caso concreto -. Em outras palavras, tanto o civil law como o common law são sistemas jurídicos dinâmicos no sentido de acomodar adequadamente particularidades às regras universais que representam uma obrigação prima facie.

\section{Referências}

ALEXY, Robert. Teoria dos direitos fundamentais. Tradução de Virgílio Afonso da Silva. 2. ed. São Paulo: Malheiros, 2014.

ÁVILA, Humberto. Teoria dos princípios: da definição à aplicação dos princípios jurídicos. 16. ed. São Paulo: Malheiros, 2015.

BÄCKER, Carsten. Regras, princípios e derrotabilidade. Revista Brasileira de Estudos Políticos, Belo Horizonte, n. 102, p. 55-82, jan./jun. 2011.

BARCELLOS, Ana Paula de. Ponderação, racionalidade e atividade jurisdicional. Rio de Janeiro: Renovar, 2005.

BELTRÁN, Jordi F.; RATTI, Giovanni B. Legal defeasibility: An introduction. The Logic of Legal

Requirements: essays on defeasibility. Great Britain: Oxford University Pres, 2012, p. 1-7.

BELTRÁN, Jordi F.; RATTI, Giovanni B. Defeasibility and legality: A survey. The Logic of Legal

Requirements: essays on defeasibility. Great Britain: Oxford University Pres, 2012, p. 11-38.

BUSTAMANTE, Thomas. Argumentação contra legem: a teoria do discurso e a justificação jurídica nos casos mais difíceis. Rio de Janeiro: Renovar, 2005.

BUSTAMANTE, Thomas. Princípios, regras e conflitos normativos: uma nota sobre a superabilidade das regras jurídicas e as decisões contra legem. Revista Direito, Estado e Sociedade, Rio de Janeiro, n. 37, p. 152-180, jul./dez. 2010.

BUSTAMANTE, Thomas. Principios, reglas y derrotabilidad. El problema de las decisiones contra legem. In: BONORINO RAMÍREZ, Pablo (org.). Teoría jurídica y decisión judicial. Madri: Bubok, 2010. p. 205284.

BUSTAMANTE, Thomas. Teoria do precedente judicial: a justificação e a aplicação de regras jurisprudenciais. São Paulo: Noeses, 2012.

CLĖVE, Clèmerson Merlin; LORENZETTO, Bruno Meneses. Constituição, governo democrático e níveis de intensidade do controle jurisdicional. Revista Judiciária do Paraná, Curitiba, v. 10, n. 10, p. 17-73, nov. 2015.

DWORKIN, Ronald Myles. Levando os direitos a sério. Tradução de Nelson Boeira. São Paulo: Martins Fontes, 2002.

GAVIÃO FILHO, Anizio Pires. Colisão de direitos fundamentais, argumentação e ponderação. Porto Alegre: Livraria do Advogado, 2011.

GAVIÃO FILHO, Anizio Pires; MUNHOZ DE ANDRADE, Rosemeri. Superabilidade das Regras Jurídicas. In: PIMENTEL, Alexandre Freire; BARROSO, Fábio Túlio; GOUVEIA, Lúcio Grassi (org.). Processo, hermenêutica e efetividade dos direitos. Recife: APPODI, 2015. p. 178-199. [e-book].

GRAEFF, Patrícia: Derrotabilidade, Vagueza e Textura Aberta: Um estudo acerca dos limites do Direito segundo Herbert Hart. Orientador: Paulo Baptista Caruso MacDonald. Coorientador: Alfredo Carlos Storck. Dissertação (Mestrado) - Universidade Federal do Rio Grande do Sul, Instituto de Filosofia e Ciências Humanas, Programa de Pós-Graduação em Filosofia, Porto Alegre, 2015. 
GUASTINI, Riccardo. Das fontes às normas. Tradução de Edson Bini - Apresentação: Heleno Taveira Tôrres. São Paulo: Quartier Latin, 2005.

HABERMAS, Jürgen (1929). Direito e democracia: entre facticidade e validade. Tradução de Flávio Beno Siebeneichler. Rio de Janeiro: Tempo Brasileiro, 1997. v.1.

HART, H. L. A. The ascription of responsability and rights. Proceedings of the Aristotelian Society, $n$. 49, 1948-1949, p. 171-194.

HART, H. L. A. O conceito de direito. 3. ed. Tradução de A. Ribeiro Mendes. Lisboa: Fundação Calouste Gulbenkian, 2001.

LIMA, Rafael Bellem de. Regras na teoria dos princípios. São Paulo: Malheiros, 2014.

MACCORMICK, Neil. Retórica e o estado de direito. Tradução de Conrado Hübner Mendes. Rio de Janeiro: Elsevier, 2008.

MACCORMICK, Neil. H. L. A. Hart. Tradução de Cláudia Santana Martins; revisão técnica Carla Henriete Beviláqua. Rio de Janeiro: Elsevier, 2010.

MARINONI, Luiz Guilherme Bittencourt. Precedentes obrigatórios. 4. ed. São Paulo: Revista dos Tribunais, 2016.

PINO, Giorgio. Neil MacCormick on interpretation, defeasibility, and the rule of law. Paper presented at the Conference Legal Reasoning and European Laws: the Perspective of Neil MacCormick (European University Institute, Florence, 21 May 2010).

RODRIGUEZ, Jorge L.; SUCAR, Germán. Las trampas de la derrotabilidad: niveles de análisis de la indeterminación del derecho. Relevancia normativa em la justificación de las decisiones judiciales. EI debate Bayón-Rodriguez sobre la derrotabilidad de las normas jurídicas. Bogotá: Universidade Externado de Colombia, 2003. p. 103-155.

SARMENTO, Daniel; SOUZA NETO, Cláudio Pereira de. Notas sobre jurisdição constitucional e democracia: a questão da "última palavra" e alguns parâmetros de autocontenção judicial. Revista Quaestio luris, Rio de Janeiro, v. 6, n. 2, p. 119-161, 2013.

SILVA, Virgílio Afonso da. Direitos fundamentais: conteúdo essencial, restrições e eficácia. 2. ed. São Paulo: Malheiros, 2010.

VASCONCELLOS, Fernando Andreoni. Hermenêutica jurídica e derrotabilidade. Curitiba: Juruá, 2010.

Recebido em: 07/02/2018

Aprovado em: 06/03/2018 